\title{
Gallic Acid Glycerol Ester Promotes Weight-Loss in Rats
}

\author{
Nagao Totani ${ }^{1 *}$, Sayuri Tateishi ${ }^{1}$, Tatsuya Takimoto ${ }^{2}$, Yukari Maeda ${ }^{2}$ and Hideaki Sasaki ${ }^{2}$ \\ ${ }^{1}$ Faculty of Nutrition, Kobe-Gakuin University (518 Arise, Ikawadani-cho, Nishi-ku, Kobe 651-2180, JAPAN) \\ ${ }^{2}$ Faculty of Pharmaceutical Sciences, Kobe-Gakuin University (1-1-3, Minatojima, Chuo-ku, Kobe 650-8586, JAPAN)
}

\begin{abstract}
Lifestyle-related diseases arise from obesity in $30-60 \%$ of cases. In recent years, food functions controlling the nutritional physiology of lipids have been a focus of disease prevention. Animal feeding experiments have revealed that esters made from gallic acid (GA) and (-)-epigallo-catechin (EGC) or linoleyl alcohol are more effective in weight-loss promotion and metabolic syndrome management than are intact GA and EGC. In this study, an ester (DOGGA) was chemically synthesized from GA and 1,2-dioleoyl glycerol and its effect was compared to that of octyl gallate (OG) and GA in male Wistar rats fed a powdered standard diet containing $7 \%$ frying oil for 12 weeks. Results revealed remarkably low body weight gains and food efficiency ratios in the DOGGA group, and the effects of OG were less pronounced than those of DOGGA. The GA group showed no difference from the control group. In addition, fecal lipid content in the DOGGA group was statistically higher than that in the control group, although organ weights and serum biochemical analyses did not differ between the groups. In conclusion, the data suggested that DOGGA promoted weight-loss more effectively than OG and GA did and that the alcohol moiety of gallate is not necessarily EGC and linoleyl alcohol.
\end{abstract}

Key words: gallic acid ester, 1, 2-dioleoyl glycerol, weight-loss, metabolic syndrome

\section{INTRODUCTION}

Lifestyle-related diseases are closely associated with obesity owing to excess accumulation of visceral fat attributable to lack of exercise and surplus caloric intake. These diseases account for more than half of the mortality in developed nations, including Japan ${ }^{1)}$. In recent years, functional food ingredients that modulate human health, especially the nutritional physiology of lipids, have been the focus of disease prevention ${ }^{2-4)}$. Unno et $a l .{ }^{5)}$ found that the addition of $1 \%$ tea catechins to the diet brought about significant reduction in the body weight gain and abdominal adipose tissue weight of rats after a 4-week feeding period compared to the control. Two-day output of feces was significantly increased by a tea catechin diet as well. Intake of tea catechins suppressed the intestinal absorption of energy nutrients via the inhibition of digestive enzymes, which may at least partially influence body fat reduction related to tea catechin intake. Ikeda et $a l .{ }^{6)}$ reported that an(-) -epicatechin (EC) and EGC mixture and a mixture of their gallates (ECG and EGCG, respectively) markedly lowered lymphatic cholesterol absorption in rats, and that the latter mixture was more effective in reducing cholesterol absorp- tion than the former owing to more effective micellar cholesterol precipitation(Fig. 1). Bose et $a l_{.}{ }^{7)}$ have investigated the effects of the major green tea polyphenol EGCG on high-fat-induced obesity, symptoms of metabolic syndrome, and the occurrence of fatty liver in mice. In mice fed a high-fat diet (HFD), supplementation with dietary EGCG treatment (3.2 g/kg diet) for 16 weeks reduced body weight gain, percent body fat, and visceral fat weight compared to mice without EGCG treatment. The body weight decrease was associated with increased fecal lipids. EGCG treatment attenuated insulin resistance, plasma cholesterol, and monocyte chemoattractant protein concentrations and decreased liver weight, liver triglycerides, and plasma alanine aminotransferase concentrations.

Jang et $a l .{ }^{8)}$ studied the effect of gallic acid (GA), linoleic $\operatorname{acid}(\mathrm{LA})$, a mixture of GA and LA (MGL), and a chemically synthesized ester (octadeca-9,12-dienyl-3,4,5-trihydroxybenzoate; GLE; GA esterified by linoleyl alcohol) mixed 1\% in a HFD on the amelioration of hyperlipidemia in C57BL/6 mice (see Fig. 1). After a 7-week feeding experiment, the average body weight of the normal diet and GLE groups was lower than that of the HFD group. Plasma lipids were

\footnotetext{
*Correspondence to: Nagao Totani, Faculty of Nutrition, Kobe-Gakuin University, 518 Arise, Ikawadani-cho, Nishi-ku, Kobe 651-2180, JAPAN

E-mail: totani@nutr.kobegakuin.ac.jp

Accepted April 18, 2011 (received for review March 28, 2011)

Journal of Oleo Science ISSN 1345-8957 print / ISSN 1347-3352 online

http://www.jstage.jst.go.jp/browse/jos/ http://mc.manusriptcentral.com/jjocs
} 
decreased in GLE-, GA-, LA-, and MGL-fed mice compared to those of HFD-fed mice. Adipose histology showed that GLE supplementation was more effective in decreasing the size of adipocytes than was supplementation in the other treatment groups. They concluded that supplementation with synthetic GLE may have a potential hypolipidemic effect on HFD-fed mice.

Catechins and GA seem to promote weight loss, and GA ester seems more effective than intact GA. Jang et al. ${ }^{8)}$ have found promise in GLE, but other combinations of GA and alcohols naturally existing in frying oil-1,2-diacyloyl glycerol for example-are also interesting. In the present study, an ester, (Z)-3-(3,4,5-trihydroxybenzoyloxy) propane-1,2-diyl dioleate(DOGGA), derived from GA and<smiles>O=C(O)c1cc(O)c(O)c(O)c1</smiles>

gallic acid (GA)

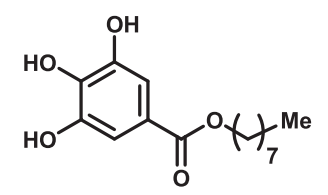

octyl gallate (OG)

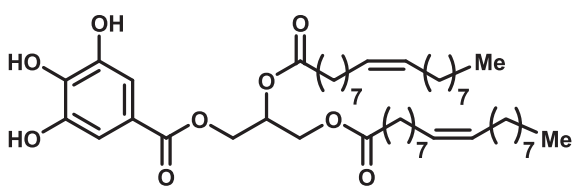

(Z)-3-(3,4,5-trihydroxybenzoyloxy)propane-1,2-diyl dioleate (DOGGA)

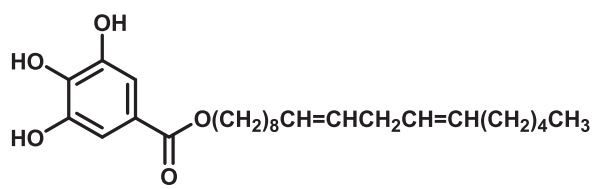

octadeca-9,12-dienyl-3,4,5-trihydroxybenzoate (GLE)<smiles>Oc1cc(O)c2c(c1)O[C@H](c1ccc(O)c(O)c1)[C@H](O)C2</smiles>

(-)-epicatechin (EC)<smiles>Oc1cc(O)c2c(c1)O[C@H](c1cc(O)c(O)c(O)c1)[C@H](O)C2</smiles>

(-)-epigallo-catechin (EGC)<smiles>O=C(O[C@H]1Cc2c(O)cc(O)cc2O[C@@H]1c1ccc(O)c(O)c1)c1cc(O)c(O)c(O)c1</smiles>

(-)-epicatechin gallate (ECG)

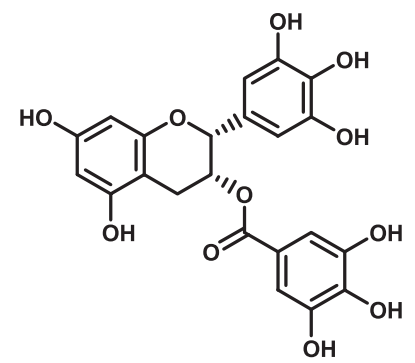

(-)-epigallo-catechin gallate (EGCG)
Fig. 1 Chemical structures of gallic acid and its esters. 1,2-dioleoyl glycerol was chemically synthesized and its weight-loss-promoting effects were compared to those of GA and OG in animal feeding experiments (see Fig. 1).

\section{EXPERIMENTAL PROCEDURES}

\subsection{Materials}

\subsubsection{Oil and chemicals added to diets}

Fresh frying oil(Nisshin Oillio, Tokyo, Japan)was purchased to make up an animal diet. Fatty acid composition of fresh oil was determined with gas chromatography as the following ${ }^{4)}$ : myristic acid, $0.1 \%$; palmitic acid, $8.3 \%$; stearic acid, $3.5 \%$; oleic acid, 33.8\%; vaccenic acid (cis-11 18:1) , 1.8\%; linoleic acid, 42.6\%; $\alpha$-linolenic acid, $7.1 \%$; and others, $2.8 \%$. OG and GA were products of Wako Pure Chemical Industries, Ltd. (Osaka, Japan). Chemical properties of the fresh oil was as follows: POV, $4.3 \mathrm{mEq} / \mathrm{kg}$; COV, 3.6; AV, 0.1; TG content, 98.8\%; IV, 124.2; Lovibond color $(\mathrm{R} / \mathrm{Y}), 0.5 / 5.0$; fresh smell. These values are typical of fresh frying oil ${ }^{3)}$.

\subsubsection{Synthesis of DOGGA}

\subsubsection{Materials}

GA hydrate, monoolein, and oleic acid were purchased from Tokyo Chemical Industry Co. Ltd. (Tokyo, Japan). Monoolein was used after purification with flash chromatography on silica gel using ethyl acetate(EtOAc)-hexane (3:2, $\mathrm{v} / \mathrm{v})$ as the eluent. Isobutyl chloroformate was purchased from Wako Pure Chemical Industries, Ltd. N-Methylmorpholine was purchased from Nacalai Tesque, Inc. (Kyoto, Japan). All other reagents and solvents were purchased from commercial sources and used without purification.

2.1.2.2 Synthesis of (isobutyl carbonic) 3,4,5-tris (isobutoxycarbonyloxy) benzoic anhydride

To a solution of GA hydrate (15.4 g, $90.5 \mathrm{mmol})$ in tetrahydrofuran (THF; $200 \mathrm{~mL}$ ) were added isobutyl chloroformate $(52.0 \mathrm{~mL}, 399 \mathrm{mmol})$ and $N$-methylmorpholine (40.0 $\mathrm{mL}, 364 \mathrm{mmol}$ ). After the solution was stirred at room temperature for $30 \mathrm{~min}$, the solvent was removed. The residue was dissolved in EtOAc, and the organic phase was washed with $10 \%$ aqueous citric acid and brine. The solution was dried over anhydrous sodium sulfate $\left(\mathrm{Na}_{2} \mathrm{SO}_{4}\right)$, and the solvent was removed under reduced pressure to give $51.3 \mathrm{~g}$ (quantitative yield) of colorless viscous oil. 2.1.2.3 Synthesis of (Z)-2-hydroxy-3-(oleoyloxy) propyl 3,4,5-tris (isobutoxycarbonyl oxy) benzoate

To a solution of (isobutyl carbonic) 3,4,5-tris (isobutoxycarbonyloxy) benzoic anhydride ( $5.02 \mathrm{~g}, 8.80 \mathrm{mmol})$ in THF (30.0 mL) were added monoolein (3.45 g, $9.68 \mathrm{mmol})$ and $N$-methylmorpholine $(1.06 \mathrm{~mL}, 9.68 \mathrm{mmol})$. After the solution was stirred at room temperature for $20 \mathrm{~h}$, the solvent was removed under reduced pressure. The residue was dissolved in EtOAc, and the organic phase was washed with $10 \%$ aqueous citric acid, saturated sodium hydrocar- 
bonate, and brine. The solution was dried over anhydrous $\mathrm{Na}_{2} \mathrm{SO}_{4}$, and the solvent was removed under reduced pressure. The crude product was purified with flash chromatography on silica gel using EtOAc-hexane (1:4, v/v) as the eluent to give $1.97 \mathrm{~g}$ ( $28 \%$ yield) of colorless viscous oil.

2.1.2.4 Synthesis of (Z)-3-(3,4,5-tris (isobutoxycarbonyloxy) benzoyloxy) propane-1,2-diyl dioleate

To a solution of oleic acid (564 mg, $2.00 \mathrm{mmol}$ ) in THF (10 $\mathrm{mL})$ were added isobutyl chloroformate $(260 \mu \mathrm{L}, 2.00$ $\mathrm{mmol})$, and $N$-methylmorpholine $(265 \mu \mathrm{L}, 2.00 \mathrm{mmol})$. After the solution was stirred at room temperature for $1 \mathrm{~h}$, a solution of (Z)-2-hydroxy-3-(oleoyloxy) propyl 3,4,5-tris (isobutoxycarbonyloxy) benzoate $(1.46 \mathrm{~g}, 1.80 \mathrm{mmol})$ in THF $(20 \mathrm{~mL}), N$-methylmorpholine $(265 \mu \mathrm{L}, 2.00 \mathrm{mmol})$, and $N, N$-dimethylaminopyridine $(1.50 \mathrm{mg}, 12.3 \mu \mathrm{mol})$ were added to the solution. After the solution was stirred at room temperature for $24 \mathrm{~h}$, the solvent was removed under reduced pressure. The residue was dissolved in EtOAc, and the organic phase was washed with $10 \%$ aqueous citric acid and brine. The solution was dried over anhydrous $\mathrm{Na}_{2} \mathrm{SO}_{4}$, and the solvent was removed under reduced pressure. The crude product was purified with flash chromatography on silica gel using EtOAc-hexane (1:5, v/v) as the eluent to give $210 \mathrm{mg}$ ( $11 \%$ yield) of colorless viscous oil.

2.1.2.5 Synthesis of (Z)-3-(3,4,5-trihydroxybenzoyloxy) propane-1,2-diyl dioleate (DOGGA)

To a solution of (Z)-3-(3,4,5-tris (isobutoxycarbonyloxy) benzoyloxy) propane-1,2- diyl dioleate (330 mg, 307 mol) in $\mathrm{THF}(40 \mathrm{~mL})$ was added $25 \%$ ammonia solution $(190 \mathrm{mg}$, $2.79 \mathrm{mmol})$. After the solution was stirred at room temperature for $13 \mathrm{~h}$, the solvent was removed under reduced pressure. The residue was dissolved in hexane, and the organic phase was washed with $10 \%$ aqueous citric acid and brine. The solution was dried over anhydrous $\mathrm{Na}_{2} \mathrm{SO}_{4}$, and the solvent was removed under reduced pressure. The crude product was purified with flash chromatography on silica gel using EtOAc-hexane $(1: 2, \mathrm{v} / \mathrm{v})$ as the eluent to give $70 \mathrm{mg}$ ( $29 \%$ yield) of yellow viscous oil.

2.1.2.6 Equipment

${ }^{1} \mathrm{H}(400 \mathrm{MHz})$ NMR spectra were recorded on a Bruker DPX-400 spectrometer. Mass spectra were measured on a Bruker microTOF-Q instrument.

2.1.3 Diets

A commercial powdered AIN93G diet without fat (Japan Clea, Tokyo, Japan) was purchased. Using a blender, the diet was mixed uniformly with $90 \mathrm{ppm}$ DOGGA $+7 \mathrm{wt} \%$ fresh oil (DOGGA group), 90 ppm OG +7 wt $\%$ fresh oil (OG group), $90 \mathrm{ppm} \mathrm{GA}+7 \mathrm{wt} \%$ fresh oil (GA group), and 7 wt $\%$ fresh oil (control), subjected to radio-sterilization of 10 kGy by Kohga Isotope (Shiga, Japan), and kept in a cold room before the animal experiment.

\subsection{Animals}

Weanling male Wistar rats aged 9 weeks were obtained from Japan SLC, Inc., Animal Experimental Center, Shizuoka, Japan.

\subsection{Animal experiment}

Thirty-two rats were housed separately in aluminum flat cages at $24 \pm 2^{\circ} \mathrm{C}$ and relative humidity $50 \pm 10 \%$, with light from 0700 to 1900 at Japan SLC, Inc., Animal Experimental Center, Shizuoka, Japan, maintained on a radiosterilized commercial pelleted diet(Labo MR Stock, Nihon Nosan Kogyo, Yokohama, Japan) for 1 week for adaptation, divided into four groups (8 rats/group) using the Statlight System (Yukms, Tokyo, Japan) and allowed ad libitum water and the diet described in section 2.1.3. After 12 weeks, animals were killed under anesthesia with pentobarbital. Serum was obtained from blood drawn from the abdominal aorta. Liver, kidneys, and retroperitoneal fat tissue were excised and weighed. Feces were collected at 11, 14, 17, 20 , and 22 weeks of age and freeze-dried before weighing. Animal care and handling were in accordance with the Ethical Agreement Concerning Care and Use of Laboratory Animals for Research and Education, Kobe-Gakuin University.

\subsection{Serum biochemical analyses}

Determinations of serum glucose (GLU), TG, phospholipids (PL), total cholesterol(T-CHO), nonesterified fatty acid (NEFA), and insulin were made with a Glucose CIItest Wako, a Triglyceride E-test Wako, a Phospholipid C-test Wako, a Cholesterol E-test Wako, a NEFA C-test Wako (Wako Pure Chemical Industries, Ltd.), and a Morinaga Insulin Measurement Kit(Morinaga Institute of Biological Science Inc., Tokyo, Japan), respectively.

\subsection{Fecal lipid extraction}

Lipids of freeze-dried feces were extracted with chloroform/methanol 2:1 v/v after milling with a TML 180 mill (Tescom, Osaka, Japan).

\subsection{Statistical analyses}

All values obtained from the animals are revealed as mean \pm SD. Data from eight animals each were analyzed using one-way analysis of variance with Dunnett's multiple comparison post hoc test. Results were considered significant at $p<0.05$.

\section{RESULTS}

\subsection{Growth of animals}

At the beginning of the animal experiment, the average body weights of the three experimental and control groups were the same, and all the animals grew normally. Body weight differences gradually became clear after 13 weeks of age, and differences between the DOGGA and OG 


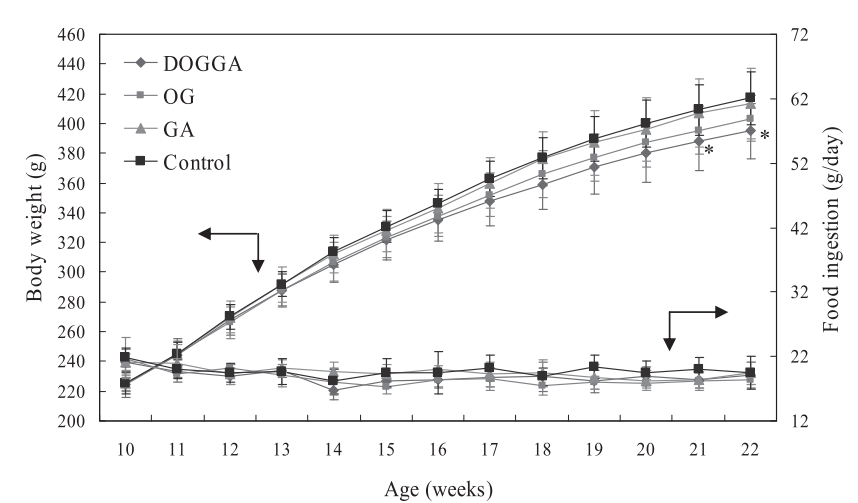

Fig. 2 Body weight increase in rats fed a diet containing gallate or gallic acid.

$* \mathrm{P}<0.05$, significantly different from the value of control. Values are expressed as mean $\pm \mathrm{SD}(\mathrm{n}=8)$.

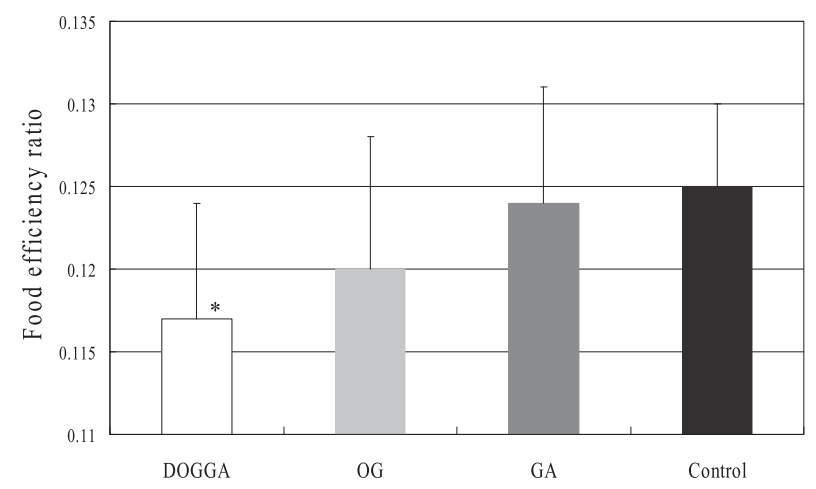

Fig. 3 Food efficiency ratio in rats fed a diet containing gallate or gallic acid.

* $\mathrm{P}<0.05$, significantly different from the value of control. Values are expressed as mean $\pm \mathrm{SD}(\mathrm{n}=8)$.

groups also increased with age (Fig. 2). At the ages of 21 and 22 weeks, the DOGGA group had a statistically significant lower body weight than that of the control group, but that of the GA group was almost the same as that of the control group. The body weight of the OG group remained between those of the DOGGA and control groups. Food efficiency ratio (FER) of the DOGGA group was remarkably lower than that of the control group, whereas no significant differences were found between the GA and the control and the OG and the control groups. FER values revealed the same relationship as that of body weight at 21 and 22 weeks of age even though food ingestion was similar (Fig. 3). No differences occurred in the weights of liver, kidneys, and retroperitoneal fat tissue in the four groups. Liver weights seemed to reflect the body weight difference slightly, however(Fig. 4). No abnormalities were found in the liver and kidneys.

Fecal lipid contents are shown in Fig. 5. Feces of all the groups weighed 1-1.3 g/day per rat without significant dif-

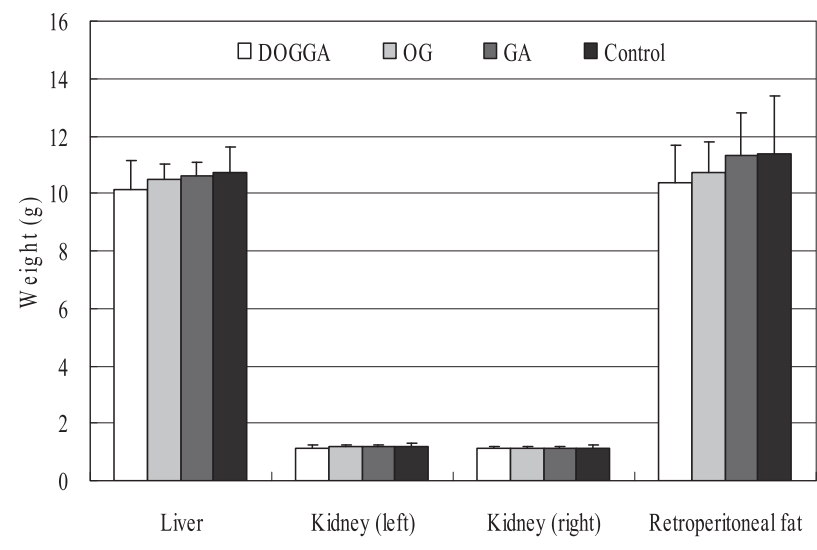

Fig. 4 Organ weight in rats fed a diet containing gallate or gallic acid.

Values are expressed as mean $\pm \mathrm{SD}(\mathrm{n}=8)$.

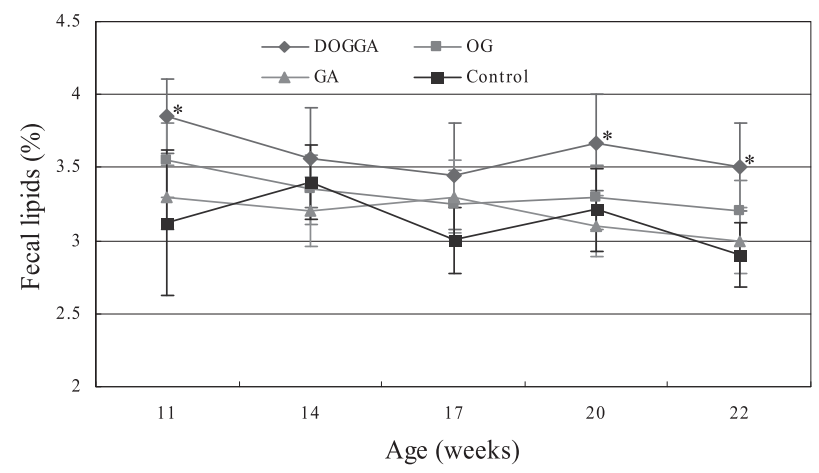

Fig. 5 Fecal lipid contents in rats fed a diet containing gallate or gallic acid.

$* \mathrm{P}<0.05$, significantly different from the value of control. Values are expressed as mean $\pm \mathrm{SD}(\mathrm{n}=8)$.

ferences, but the lipid content of the DOGGA group was remarkably higher than that of the control group at 11, 20, and 22 weeks of age.

\subsection{Serum biochemical analyses}

Serum biochemical analyses did not reveal statistically significant differences in the levels of TG, GLU, PL, T-CHO, NEFA, or insulin (Fig. 6).

\section{DISCUSSION}

Niho et $a .^{9}{ }^{9)}$ studied the subchronic toxicity of GA in F344 rats by feeding a diet containing $0-5 \%$ GA for 13 weeks and have determined that $0.2 \%$ was a no-observedadverse-effect level in rats. This level translates into 119 and $128 \mathrm{mg} / \mathrm{kg}$ per day for male and female rats, respectively, suggesting no toxicity at $90 \mathrm{ppm}$ GA in the diet used in the present study: rats weighing 223 - 447 g ingested the 


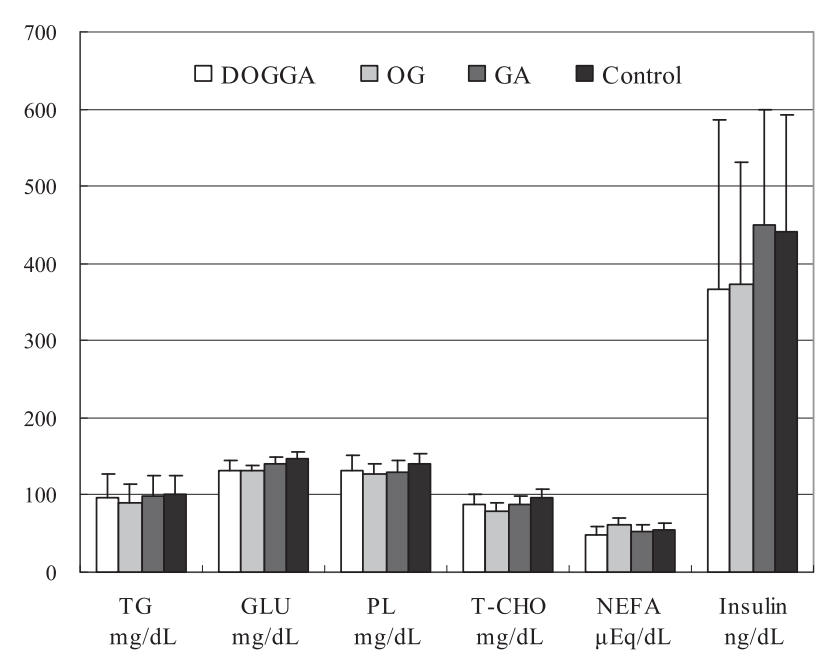

Fig. 6 Serum biochemical values in rats fed a diet containing gallate or gallic acid.

Values are expressed as mean $\pm \mathrm{SD}(\mathrm{n}=8)$.

diet at levels between 17 and $22 \mathrm{~g} /$ day. Hsu et al. ${ }^{10)}$ investigated the effects of GA on HFD-induced dyslipidemia and hepatosteatosis in rats. GA was given as a supplement at levels of 50 and $100 \mathrm{mg} / \mathrm{kg}$ per rat for a period of 10 weeks. The results showed that body weight and the weights of the liver and adipose tissues were significantly decreased in the HFD-GA groups compared to those of the HFD group without any adverse effects from GA. Thus, GA has been shown to be safe when used at these levels. In addition, our study used GA esters, which are likely safer than intact GA; in general, polar compounds lose chemical activity when those functional groups are blocked.

Weight-loss-promoting effects of polyphenols in green tea $^{5-7,11-15)}$, tea ${ }^{16)}$, oolong tea ${ }^{17)}$, rooibos extract ${ }^{18)}$, beer $^{19)}$, apple $^{20)}$, dark chocolate ${ }^{21)}$, longan flower water extract ${ }^{22)}$,' and other compounds have been observed in animals and humans. Han et al. ${ }^{23)}$ isolated an anti-obesity effector from polyphenol fractions of Salix matsudana and identified it to be a flavonoid glucoside. These polyphenols are analogues of catechins and flavones, which are similar in chemical structure. GLE, to which Jang et al. ${ }^{8)}$ turned their attention as an anti-obesity effector, differs from catechins and flavones in structure, however. In the present study, intact GA and OG did not clearly show weight-loss-promoting effects, whereas GA esterified by 1,2-dioleoyl glycerol did. Thus, it would be of interest to investigate the effects of GA esterified with an acid at its $\mathrm{OH}$ group.

Bose $e t a l .{ }^{7)}$ have reported that body weight decrease EGCG of HFD-fed mice is associated with increased fecal lipids, plasma cholesterol, etc. Jang et $a l^{8)}$ have proved hypolipidemic activity in GLE (weight loss and decreased levels of plasma T-CHO, low-density lipoprotein cholesterol, TG, etc.) but did not carry out fecal analyses. The present study showed that DOGGA decreased body weight gains and FER while increasing fecal lipid content. Thus, our results partially agree with those of Bose $e t a l .{ }^{7)}$ and Jang $e t$ $a l^{8}{ }^{8}$, without significant differences in serum biochemical analyses, probably because the amount of DOGGA was low compared to that in the other experiments. It is noteworthy, however, that the level of DOGGA in the diet was 1/36 and $1 / 111$ of that used by Bose et $a l^{7}{ }^{7}$ and Jang et $a l^{8}{ }^{8}$, respectively, in studies using a HFD that contained fat equivalent to $60 \%$ energy $^{7)}$ and $23.8 \%$ lard $^{8)}$, respectively, to generate obesity. Our diet contained $7 \%$ oil, to match the oil content in a standard rat diet ${ }^{3)}$.

DOGGA promoted weight-loss by increasing fecal lipid content without any adverse effects on appetite or organs. In a previous report ${ }^{3)}$, we demonstrated that frying oil thermally processed with soybean protein followed by filtration was related to weight-loss promotion in Wistar rats. The major mechanism of the finding was that the oil stimulated peristalsis in the gastrointestinal tract, and colon contents were actively excreted ${ }^{24,25)}$. This mechanism agrees well with the findings of Unno et $a l^{5}{ }^{5}$ in which tea catechins were used as anti-obesity effectors. Further study is required to clarify why DOGGA did not increase fecal amounts but increased fecal lipids. Intake of DOGGA may have suppressed the intestinal absorption of lipids via the inhibition of digestive enzymes ${ }^{5}$. In conclusion, our data suggested that DOGGA promoted weight loss more effectively than OG and GA did, and that the alcohol moiety of gallate must not necessarily be made up of EGC and linoleyl alcohol to promote weight loss.

\section{ACKNOWLEDGMENT}

This work was supported partly by grants from the Life Science Center of Kobe-Gakuin University.

\section{References}

1) Yanagita, T.; Nagao, K. Prevention of metabolic syndrome with bioactive lipids. Sci. \& Ind. 82, 493-498 (2008).

2) Yanagita, T.; Nagao, K. Functional lipids and the prevention of the metabolic syndrome. Asia Pac. J. Clin. Nutr. 17, 189-191 (2008).

3) Totani, N.; Morita, A.; Nishinaka, M.; Tateishi, S.; Kida, H. Novel body weight-loss promoting oil prepared with vegetable protein. J. Oleo Sci. 59, 41-48 (2010).

4) Wang, Y. M.; Rahman, S. M.; Nagao, K.; Arao, K.; Inoue, N.; Yanagita, T. Comparison of the effects of triacylglycerol-CLA and free fatty acid-CLA on hepatic lipid metabolism in PLETF obese rats. J. Oleo Sci. 52, 121-128 (2003).

5) Unno, T.; Osada, C.; Motoo, Y.; Suzuki, Y.; Kobayashi, 
M.; Nozawa, A. Dietary tea catechins increase fecal energy in rats. J. Nutr. Sci. Vitaminol. 55, 447-451 (2009).

6) Ikeda, I.; Imasato, Y.; Sasaki, E.; Nakayama, M.; Nagao, H.; Takeo, T.; Yayabe, F.; Sugano, M. Tea catechins decrease micellar solubility and intestinal absorption of cholesterol in rats. Biochim. Biophys. Acta 1127, 141-146 (1992).

7) Bose M.; Lambert, J. D.; Ju, J.; Reuhl, K. R.; Shapses, S. A.; Yang, C. S. The Major green tea polyphenol, (-)-epigallocatechin-3-gallate, inhibits obesity, metabolic syndrome, and fatty liver disease in high-fat fed mice. $J$. Nutr. 138, 1677-1683(2008).

8) Jang, A.; Srinivasan, P.; Lee, N. Y.; Song, H. P.; Lee J. W.; Jo, C. Comparison of hypolipidemic activity of synthetic gallic acid-linoleic acid ester with mixture of gallic acid and linoleic acid, gallic acid, and linoleic acid on high-fat diet induced obesity in C57BL/6 Cr Slc mice. Chem. Biol. Interact. 174, 109-117(2008).

9) Niho, N.; Shibutani, M.; Toyoda, K.; Uneyama, C.; Takahashi, N.; Hirose, M. Subchronic toxicity study of gallic acid by oral administration in F344 rats. Food Chem. Toxicol. 39, 1063-1070(2001).

10) Hsu, C. L.; Yen, G. C. Effect of gallic acid on high fat diet-induced dyslipidaemia, hepatosteatosis and oxidative stress in rats. Br. J. Nutr. 98, 727-735 (2007).

11) Grove, K. A.; Lambert, J. D. Laboratory, epidermiological, and human intervention studies show that tea (Camellia sinensis) may be useful in the prevention of obesity. J. Nutr. 140, 446-453(2010).

12) Chen, D; Milacic, V.; Chen, M. S.; Wan, S. B.; Lam, W. H.; Huo, C.; Landis-Piwowar, K. R.; Cui, Q. C.; Wali, A.; Chan, T. H.; Dou, Q. P. Tea polyphenol, their biological effects and potential molecular targets. Histol. Histopathol. 23, 487-496 (2008).

13) Lee, M. S.; Kim, C. T.; Kim, Y. Green tea(-)-epigallocatechin-3-gallate reduces body weight with regulation of multiple genes expression in adipose tissue of diet-induced obese mice. Ann. Nutr. Metab. 54, 151-157(2009).

14) Wolfram, S.; Raederstorff, D.; Wang, Y; Teixeira, S. R.; Elste, V.; Weber, P. TEAVIGO (epigallocatechin gallate) supplementation prevents obesity in rodents by reducing adipose tissue mass. Ann. Nutr. Metab. 49, 54-63 (2005).

15) Klaus, S.; Pueltz, S.; Thoene-Reineke, C.; Wolfram,S. Epigallocatechin gallate attenuates diet-induced obesity in mice by decreasing energy absorption and increasing fat oxidation. Int. J. Obes. 29, 615-623(2005).
16) Uchiyama, S.; Taniguchi, Y.; Saka, A.; Yoshida, A.; Yajima, H. Prevention of diet-induced obesity by dietary black tea polyphenols extract in vitro and in vivo. Nutrition 2010 June 2. (Epub ahead of print)

17) Hsu, T. F.; Kusumoto, A.; Abe, K.; Kiso, Y.; Wang, M. F.; Yamamoto, S. Polyphenol-enriched oolong tea increases fecal lipid excretion. Eur. J. Clin. Nutr. 60, 1330-1336 (2006).

18) Beltan,-Debon, R.; Rull, A.; Rodriguez-Sanabria, F.; Iswaldi, I.; Herranz-Lopez, M.; Aragones, G.; Camps, J.; Alonso-Villaverde, C.; Menendez, J.A.; Micol, V.; Segura-Carretero, A.; Joben, J. Continuous administration of polyphenols from aqueous rooibos (Aspalathus linearis) extract ameliorates dietary-induced metabolic disturbances in hyperlipidemic mice. Phytomedicine, 2011 Jan 4. (Epub ahead of print).

19) Miura, Y.; Hosono, M.; Oyamada, C.; Odai, H.; Oikawa, S.; Kondo, K. Dietary isohumulones, the bitter components of beer, raise plasma HDL-cholesterol levels and reduce liver cholesterol and triacylglycerol contents similar to PPARalpha activation in C57BL/6 mice. Br. J. Nutr. 93, 559-567(2005).

20) Nagasako-Akazome, Y.; Kanda, T.; Ohtake, Y.; Shimasaki, H.; Kobayashi, T. Apple polyphenols influence cholesterol metabolism in healthy subjects with relatively high body mass index. J.Oleo Sci. 56, 417-428(2007).

21) Almoosawi, S.; Fyfe, L.: Ho, C.; Al-Dujaili, E. The effect of polyphenol-rich dark chocolate on fasting capillary whole blood glucose, total cholesterol, blood pressure and glucocorticoids in healthy overweight and obese subjects. Br. J. Nutr. 103, 842-850 (2010).

22) Yang, D. J.; Chang, Y. Y.; Hsu, C. L.; Liu, C. W.; Lin, Y. L.; Lin, Y. H.; Liu, K. C.; Chen, Y. C. Antiobesity and hypolipidemic effects of polyphenol-rich longan(Dimocarpus longans Lour.) flower water extract in hypercaloric dietary rats. J. Agric. Food Chem. 58, 2020-2027 (2010).

23) Han, L. K.; Sumiyoshi, M.; Zheng, Y. N.; Okuda, H.; Kimura, Y. Anti-obesity action of Salix matsudana leaves (Part 2). Isolation of anti-obesity effectors from polyphenol fractions of Salix matsudana. Phytother. Res. 17, 1195-1198(2003).

24) Totani, N.; Araki, Y.; Tateishi, S. Effects of oil thermally processed with vegetable protein on gastrointestinal tract content transfer. J. Oleo Sci. 59, 115-120 (2010).

25) Totani, N.; Tateishi, S.; Morita, A.; Kida, H. The mechanism of weight-loss promoting effects of oil heated with vegetable protein. J. Oleo Sci. 59, 463-470 (2010). 